\title{
Granulocyte-Colony Stimulating Factor Reduces Cocaine-Seeking and Downregulates Glutamatergic Synaptic Proteins in Medial Prefrontal Cortex
}

\author{
${ }^{(}$Rebecca S. Hofford, ${ }^{1,2}$ Tanner J. Euston, ${ }^{1,2}$ Rashaun S. Wilson, ${ }^{3,4}$ Katherine R. Meckel, ${ }^{2,5}$ Emily G. Peck, ${ }^{6}$ \\ Arthur Godino, ${ }^{2,5}$ Joseph A. Landry, ${ }^{1,2,5}$ Erin S. Calipari, ${ }^{7,8,9,10,11,12}{ }^{\circledR}$ TuKiet T. Lam, ${ }^{3,4}$ and ${ }^{\circledR}$ Drew D. Kiraly ${ }^{1,2,5,13}$ \\ ${ }^{1}$ Department of Psychiatry, Icahn School of Medicine at Mount Sinai, New York, New York 10029, ${ }^{2}$ Friedman Brain Institute, Icahn School of Medicine at \\ Mount Sinai, New York, New York 10029, ${ }^{3}$ Department of Molecular Biophysics and Biochemistry, Yale University, New Haven, CT 06510, ${ }^{4}$ WM Keck \\ Biotechnology Resource Laboratory, Yale University, New Haven, Connecticut 06510, ${ }^{5}$ Nash Family Department of Neuroscience, Icahn School of Medicine at \\ Mount Sinai, New York, New York 10029, ${ }^{6}$ Department of Physiology and Pharmacology, Wake Forest School of Medicine, Winston-Salem, North Carolina \\ 27101, Departments of ${ }^{7}$ Pharmacology, ${ }^{8}$ Molecular Physiology and Biophysics, ${ }^{9}$ Psychiatry and Behavioral Sciences, Vanderbilt University, Nashville, \\ Tennessee 37232, ${ }^{10}$ Vanderbilt Brain Institute, Vanderbilt University, Nashville, Tennessee 37232, ${ }^{11}$ Vanderbilt Center for Addiction Research, \\ Vanderbilt University, Nashville, Tennessee 37232, ${ }^{12}$ Vanderbilt Institute for Infection, Immunology, and Inflammation, Vanderbilt University, Nashville, \\ Tennessee 37232, and ${ }^{13}$ Seaver Center for Autism, Icahn School of Medicine at Mount Sinai, New York, New York 10029
}

Psychostimulant use disorder is a major public health issue, and despite the scope of the problem there are currently no Food and Drug Administration (FDA)-approved treatments. There would be tremendous utility in development of a treatment that could help patients both achieve and maintain abstinence. Previous work from our group has identified granulocyte-colony stimulating factor (G-CSF) as a neuroactive cytokine that alters behavioral response to cocaine, increases synaptic dopamine release, and enhances cognitive flexibility. Here, we investigate the role of G-CSF in affecting extinction and reinstatement of cocaine-seeking and perform detailed characterization of its proteomic effects in multiple limbic substructures. Male Sprague Dawley rats were injected with PBS or G-CSF during (1) extinction or (2) abstinence from cocaine self-administration, and drug seeking behavior was measured. Quantitative assessment of changes in the proteomic landscape in the nucleus accumbens (NAc) and medial prefrontal cortex (mPFC) were performed via data-independent acquisition (DIA) mass spectrometry analysis. Administration of G-CSF during extinction accelerated the rate of extinction, and administration during abstinence attenuated cue-induced cocaine-seeking. Analysis of global protein expression demonstrated that G-CSF regulated proteins primarily in $\mathrm{MPFC}$ that are critical to glutamate signaling and synapse maintenance. Taken together, these findings support G-CSF as a viable translational research target with the potential to reduce drug craving or seeking behaviors. Importantly, recombinant G-CSF exists as an FDA-approved medication which may facilitate rapid clinical translation. Additionally, using cutting-edge multiregion discovery proteomics analyses, these studies identify a novel mechanism underlying G-CSF effects on behavioral plasticity.

Key words: cocaine; cytokine; neuroimmune; reinstatement

Significance Statement

Pharmacological treatments for psychostimulant use disorder are desperately needed, especially given the disease's chronic, relapsing nature. However, there are currently no Food and Drug Administration (FDA)-approved pharmacotherapies. Emerging evidence suggests that targeting the immune system may be a viable translational research strategy; preclinical studies have found that the neuroactive cytokine granulocyte-colony stimulating factor (G-CSF) alters cocaine reward and reinforcement and can enhance cognitive flexibility. Given this basis of evidence we studied the effects of G-CSF treatment on extinction and reinstatement of cocaine seeking. We find that administration of G-CSF accelerates extinction and reduces cue-induced drug seeking after cocaine selfadministration. In addition, G-CSF leads to downregulation of synaptic glutamatergic proteins in medial prefrontal cortex (mPFC), suggesting that G-CSF influences drug seeking via glutamatergic mechanisms.

Received June 8, 2020; revised Dec. 8, 2020; accepted Dec. 14, 2020.

Author contributions: R.S.H., E.S.C., and D.D.K. designed research; R.S.H., T.J.E., R.S.W., K.R.M., E.G.P., A.G., J.A.L., E.S.C., T.T.L., and D.D.K. performed research; J.A.L. contributed unpublished reagents/analytic tools; R.S.H., T.J.E., R.S.W., E.G.P., A.G., E.S.C., T.T.L., and D.D.K. analyzed data; R.S.H. and D.D.K. wrote the paper.

Discovery proteomic datasets are posted to the publicly available ProteomeXChange server with accession number: PXD019485.
This work was supported by National Institutes of Health (NIH) Grants DA-044308, DA-049568, DA-051551 (to D.D.K.) and DA-042111 and DA-048931 (to E.S.C.) as well as by National Alliance for Research on Schizophrenia and Depression Young Investigator Awards to R.S.H., E.S.C., and D.D.K. The Orbitrap Fusion mass spectrometer and the Offline UPLC utilized were supported in part by NIH Shared Instrument Grant Grants 1S100D019967-0 and 1S100D0D018034-01, respectively, and Yale School of Medicine. This work was also supported by the Yale/National Institute on Drug Abuse (NIDA) Neuroproteomics Center Grant DA018343. Cocaine was provided by the NIDA drug supply program. 


\section{Introduction}

Pathologic substance use disorders (SUDs) are debilitating psychiatric conditions characterized by a pattern of escalating and dysregulated substance use followed by a chronic cycle of abstinence and relapse (American Psychiatric Association, 2013). In SUD patients, the propensity to relapse is a major impediment to successful treatment, and increases in cocaine craving following prolonged periods of abstinence have been seen in both human subjects and rodent models (Sinha, 2011; Parvaz et al., 2016). Despite the immense societal burden of illness, there are currently no Food and Drug Administration (FDA)-approved medications for the treatment of psychostimulant use disorder, and behavioral interventions alone are only marginally effective at ameliorating this disease (Penberthy et al., 2010). In recent years, there has been increased interest in non-traditional pharmacological approaches to treat cocaine addiction. There is growing evidence for neuroimmune interactions in multiple neuropsychiatric disorders, including schizophrenia, depression, and addiction (Hodes et al., 2015; Lacagnina et al., 2017; Miller and Goldsmith, 2017; Hofford et al., 2019). This has led to an emerging body of research targeting neuroimmune interactions as possible translational research targets in addiction and other neuropsychiatric diseases (Farokhnia et al., 2020).

Recently, we have identified granulocyte-colony stimulating factor (G-CSF) as a neuroactive cytokine with high relevance to SUD and motivation. While G-CSF was initially identified for its ability to mobilize stem cells from the bone marrow, numerous studies have found that centrally it functions as a trophic factor important for learning and memory (Diederich et al., 2009b), and it is neuroprotective in multiple models of neurologic disease (Meuer et al., 2006; Ridwan et al., 2014). Recently, we found that G-CSF is increased in serum and brain following repeated cocaine, and levels of G-CSF positively correlated with cocaine intake (Calipari et al., 2018). Endogenous G-CSF signaling is necessary for the development of cocaine conditioned place preference (CPP) and enhancing levels of G-CSF through repeated systemic injections increases CPP and self-administration of low doses of cocaine (Calipari et al., 2018). In line with previous studies implicating G-CSF in learning and memory (Diederich et al., 2009a,b), we also demonstrated that G-CSF enhanced behavioral flexibility in an operant reversal task (Kutlu et al., 2018). Together, this suggests that G-CSF might be influencing cocaine reward and reinforcement by affecting motivation for cocaine or learning processes associated with operant self-administration.

Two of the most common ways to assess relapse in preclinical models are reinstatement after extinction and re-exposure to drug cues after a period of abstinence (Grimm et al., 2001; Dong et al., 2017; Farrell et al., 2018). All models of relapse involve recall of previously learned response-outcome contingencies and require intact functioning of the mesolimbic dopaminergic system (Kalivas et al., 2005; Hyman et al., 2006; Farrell et al., 2018), parts of which are known to be affected by G-CSF (Mervosh et al., 2018; Brady et al., 2019). Active self-administration, extinction, and reinstatement all recruit nucleus accumbens (NAc) and medial prefrontal cortex (mPFC; Kalivas and McFarland, 2003; Hyman et al., 2006; Peters et al., 2009), making these areas potential targets of G-CSF action in cocaine reinforcement, extinction, and reinstatement.

The authors declare no competing financial interests.

Correspondence should be addressed to Drew D. Kiraly at drew.kiraly@mssm.edu.

https://doi.org/10.1523/JNEUROSCI.1452-20.2020

Copyright (@) 2021 the authors
Given the potential for G-CSF to alter the behavioral plasticity associated with drug-seeking, the current study measured the effect of G-CSF on both cocaine extinction and cocaine-seeking after a period of abstinence. Since G-CSF potentiated cocaine reward in CPP, increased cocaine intake during self-administration (Calipari et al., 2018), and enhanced reversal learning (Kutlu et al., 2018), these experiments helped determine whether G-CSF exerts its effects on motivation or learning processes. Finally, to explore the underlying molecular mechanisms of G-CSF, we performed comprehensive discovery proteomics analysis on the NAc and dorsal mPFC following cocaine reinstatement. The insights gained into the mechanism of action of G-CSF could support the repurposing of G-CSF or the design of more targeted therapeutics for psychostimulant use disorder.

\section{Materials and Methods}

\section{Animals and housing}

Adult male Sprague Dawley rats (ENVIGO-Harlan), weighing between 280 and $300 \mathrm{~g}$ were pair-housed in a room with controlled temperature and humidity on a 24 -h reverse light-dark cycle (lights on at 7 P.M.). All rats had ad libitum access to food and water before the start of any experiments. All animal procedures were approved by the IACUC at the Icahn School of Medicine at Mount Sinai and all practices conformed to the Guide for the Care and Use of Laboratory Animals (National Research Council 2010). Separate rats were used in experiments 1 and 2.

\section{Cocaine self-administration}

Self-administration, extinction, and cocaine seeking occurred in standard two-lever operant boxes equipped with two retractable levers, a syringe pump, and two jewel lights placed above each lever (Med Associates Inc). Operant chambers used in experiment 1 were equipped with infrared beams that recorded movements via beam breaks continuously throughout active self-administration and extinction. Before surgery, rats were anesthetized with a ketamine/xylazine cocktail (100/ $10 \mathrm{mg} / \mathrm{kg}$ ) before placement of an indwelling catheter (Plastics One) into the right jugular vein. Rats were allowed to recover for 3-7 d before the start of self-administration and were immediately returned to pair-housing after recovery. Sessions were initiated by the insertion of an active and inactive lever. Lever presses on the active lever were reinforced on a fixed ratio 1 schedule and resulted in a $5.9-\mathrm{s}$ infusion of $0.8 \mathrm{mg} / \mathrm{kg} / \mathrm{infu}-$ sion $(0.1 \mathrm{ml})$ cocaine and concurrent illumination of both cue lights (experiment 1) or the cue light above the active lever (experiment 2). There was a signaled time-out of $20 \mathrm{~s}$; active lever presses during the time-out were recorded but did not result in cocaine infusion. Active self-administration sessions lasted $3 \mathrm{~h}$ once daily for $10 \mathrm{~d}$. Presses on the inactive lever had no programmed consequence. Position of the active lever was counterbalanced across rats. All rats were placed on food restriction starting the day before self-administration start and continuing throughout the entire study by administration of 18 -g food/rat delivered after the end of the session. This level of food restriction kept rats at approximately $90 \%$ of their starting body weight; an unrestricted diet is projected to cause weight gain in Sprague Dawley rats over this period of time (https://www.envigo.com/model/hsd-sprague-dawley-sd).

\section{Extinction}

All rats (both experiment 1 and experiment 2) underwent extinction. Extinction sessions ran daily for $5 \mathrm{~d}$ starting the day after rats' last selfadministration session. Sessions were $3 \mathrm{~h}$ and were initiated as described above. During this phase, active lever presses no longer had any programmed consequence.

\section{Abstinence and cocaine seeking tests}

Rats in experiment 2 were left in their home cages for $7 \mathrm{~d}$ following extinction training. For the cue-induced cocaine seeking test, rats were returned to the operant boxes for $30 \mathrm{~min}$ where responding on the previously active lever caused illumination of the light cue but did not result in cocaine infusion. Rats were returned to the colony and remained in 
their home cage for another $3 \mathrm{~d}$. For the cocaine-primed seeking test, rats were injected with $10 \mathrm{mg} / \mathrm{kg}$ cocaine (intraperitoneally) immediately before placement into the operant boxes for $30 \mathrm{~min}$ where lever presses on the previously active lever had no programmed consequence.

\section{Drugs}

Cocaine hydrochloride was provided by the National Institute on Drug Abuse (NIDA) drug supply program and was diluted in saline. Rat GCSF was purchased from GenScript Corp and was diluted with sterile PBS to a concentration of $50 \mu \mathrm{g} / \mathrm{ml}$.

\section{Experimental timeline}

Experiment 1

After self-administration training, rats were divided into PBS and G-CSF groups, such that levels of responding during acquisition did not differ. Rats received either PBS or $50 \mu \mathrm{g} / \mathrm{kg}$ G-CSF (intraperitoneally) once daily $30 \mathrm{~min}$ before the start of each extinction session. This dose was chosen based on previous work in rats that found $50 \mu \mathrm{g} / \mathrm{kg}$ was sufficient to influence cocaine self-administration at low doses (Calipari et al., 2018). Five rats failed to acquire cocaine self-administration and were dropped from the study before extinction because of patency loss for final subject sizes of PBS $n=6$ and G-CSF $n=7$.

\section{Experiment 2}

Rats were divided into PBS and G-CSF treatment groups at the end of extinction, such that levels of responding during acquisition and extinction did not differ between groups. Rats were injected once daily with PBS or $50 \mu \mathrm{g} / \mathrm{kg}$ G-CSF (intraperitoneally) during abstinence and 30 min before each seeking test session. Rats were run in two cohorts; in total, seven rats were dropped from the study before extinction because of loss of patency or, in one instance, inconsistent cocaine intake over days for final subject sizes of PBS $n=8$ and G-CSF $n=9$.

\section{Tissue collection}

Rats from the second cohort of experiment 2 were euthanized by rapid decapitation $30 \mathrm{~min}$ after the conclusion of the cocaine-primed seeking test (i.e., $1 \mathrm{~h}$ after cocaine prime injection). Whole brains were placed on an ice-cold brain slicing matrix; 2-mm-thick sections containing the NAc core and the mPFC (consisting of anterior cingulate and prelimbic cortices) were removed with a 14 gauge (NAc) or 12 gauge (mPFC) blunt needle using the anterior commissure (NAc) or corpus callosum (mPFC) as landmarks. Subject sizes for proteomics analysis were PBS $n=4$ and $\mathrm{G}-\mathrm{CSF} n=5$.

\section{Sample preparation for liquid chromatography with tandem mass spectrometry (LC-MS/MS)}

NAc and mPFC tissues were lysed with a probe sonicator in solubilization buffer ( $8 \mathrm{M}$ urea $0.4 \mathrm{~mm}$, ammonium bicarbonate $\mathrm{pH} 8$ ). Lysate was centrifuged at max speed for $10 \mathrm{~min}$ at $10^{\circ} \mathrm{C}$ in a tabletop centrifuge to pellet cellular debris. Supernatant containing proteins $(50 \mu \mathrm{g})$ was placed into an Eppendorf tube, and the volume was adjusted to $100 \mu \mathrm{l}$ with solubilization buffer. Proteins were reduced with $5 \mu \mathrm{l}$ of $200 \mathrm{~mm}$ dithiothreitol (DTT) and incubated at $37^{\circ} \mathrm{C}$ for $30 \mathrm{~min}$. They were then alkylated with $5 \mu \mathrm{l}$ of $500 \mathrm{~mm}$ iodoacetamide (IAM) and incubated in the dark at room temperature for $30 \mathrm{~min}$. After diluting with water to bring urea concentration to $2 \mathrm{M}$, sequencing-grade trypsin (Promega) was added at a weight ratio of $1: 20$ (trypsin/protein) and incubated at $37^{\circ} \mathrm{C}$ for $16 \mathrm{~h}$. The digested samples were then acidified with $0.1 \%$ formic acid, desalted using C18 spin columns (The Nest Group), and dried in a rotary evaporator. The samples were resuspended in $0.2 \%$ trifluoroacetic acid (TFA) and $2 \%$ acetonitrile $(\mathrm{ACN})$ in water before LC-MS/MS analysis.

\section{Data-independent acquisition (DIA)}

DIA LC-MS/MS was performed using a nanoACQUITY UPLC system (Waters Corporation) connected to an Orbitrap Fusion Tribrid (ThermoFisher Scientific) mass spectrometer. After injection, the samples were loaded into a trapping column (nanoACQUITY UPLC Symmetry C18 Trap column, $180 \mu \mathrm{m} \times 20 \mathrm{~mm}$ ) at a flow rate of $5 \mu \mathrm{l} /$ min and separated with a C18 column (nanoACQUITY column
Peptide BEH C18, $75 \mu \mathrm{m} \times 250 \mathrm{~mm}$ ). The compositions of mobile phases A and B were $0.1 \%$ formic acid in water and $0.1 \%$ formic acid in ACN, respectively. The peptides were separated and eluted with a gradient extending from $6 \%$ to $35 \%$ mobile phase B in $90 \mathrm{~min}$ and then to $85 \%$ mobile phase $\mathrm{B}$ in additional $15 \mathrm{~min}$ at a flow rate of 300 $\mathrm{nl} / \mathrm{min}$ and a column temperature of $37^{\circ} \mathrm{C}$. Column regeneration and up to three blank injections were conducted in between all sample injections. The data were acquired with the mass spectrometer operating in a DIA mode with an isolation window width of $25 \mathrm{~m} / \mathrm{z}$. The full scan was performed in the range of 400-1000 m/z with "use quadrupole isolation" enabled at an Orbitrap resolution of 120,000 at $200 \mathrm{~m} /$ $\mathrm{z}$ and automatic gain control (AGC) target value of $4 \times 105$. Fragment ions from each peptide MS2 were generated in the C-trap with higher-energy collision dissociation (HCD) at a collision energy of $28 \%$ and detected in the Orbitrap at a resolution of 60,000.

DIA spectra were searched against a Rattus norvegicus brain proteome fractionated spectral library generated from DDA LC-MS/MS spectra (collected from the same Orbitrap Fusion mass spectrometer) using Scaffold DIA software v. 1.1.1 (Proteome Software). Within Scaffold DIA, raw files were first converted to the mzML format using ProteoWizard v. 3.0.11 748. The samples were then aligned by retention time and individually searched with a mass tolerance of $10 \mathrm{ppm}$ and a fragment mass tolerance of $10 \mathrm{ppm}$. The data acquisition type was set to DIA, and the maximum missed cleavages was set to 2. Fixed modifications included carbamidomethylation of cysteine residues (+57.02). Dynamic modifications included phosphorylation of serine, threonine, and tyrosine $(+79.96)$, deamination of asparagine and glutamine $(+0.98)$, oxidation of methionine and proline $(+15.99)$, and acetylation of lysine (+42.01). Peptides with charge states between 2 and 4 and 6-30 amino acids in length were considered for quantitation, and the resulting peptides were filtered by Percolator v. 3.01 at a threshold FDR of 0.01 . Peptide quantification was performed by EncyclopeDIA v. 0.6.12 (Searle et al., 2018), and six of the highest quality fragment ions were selected for quantitation. Proteins containing redundant peptides were grouped to satisfy the principles of parsimony, and proteins were filtered at a threshold of two peptides per protein and an FDR of $1 \%$. The mass spectrometry proteomics data have been deposited to the ProteomeXchange Consortium via the PRIDE (Perez-Riverol et al., 2019) partner repository with the dataset identifier PXD019485.

\section{Pathway analysis}

Proteins were excluded from analysis if they were not detected in $>50 \%$ of all samples regardless of treatment. Pairwise comparisons of the $\log _{10}$ median intensity of every remaining protein and protein group were made using Scaffold DIA proteomics analysis software (http://www. proteomesoftware.com/products/dia/). Significantly upregulated and downregulated proteins from each brain region were separately uploaded into the open source pathway analysis software package G:Profiler (Raudvere et al., 2019; https://biit.cs.ut.ee/gprofiler/gost) to identify significantly enriched Gene Ontologies (GO) and Kyoto Encyclopedia of Genes and Genomes (KEGG) pathways using an FDR corrected $p<0.05$. Given that this software utilizes gene names for identifying pathways, all protein names were converted to gene names before pathway analysis using the Uniprot database (https://www.uniprot.org/uploadlists/). For comparative pathway analyses, related pathway terms were reduced using Revigo (Supek et al., 2011; http://revigo.irb.hr/). Upregulated and downregulated proteins from NAc and mPFC were separately uploaded into the STRING database (Szklarczyk et al., 2019; https://string-db.org/) and enrichment of protein-protein interactions (PPIs) was assessed with the "multiple proteins" query using default settings. Statistical analyses for PPI enrichment, and number of predicted interactions per protein (average node degree), were performed using the STRING analysis software. For visualization of PPI networks disconnected nodes were removed from the image, and node size was adjusted to correspond to the $-\log (p)$ relative to PBS control. Portions of Figures 1, 2, 5 were created with BioRender.com.

\section{Parallel reaction monitoring (PRM) LC-MS/MS}

PRM LC-MS/MS was performed as a validation test on samples used for DIA LC-MS/MS using a nanoACQUITY UPLC system (Waters 


\section{A: Experiment 1 Timeline}

$0.8 \mathrm{mg} / \mathrm{kg} / \mathrm{infusion}$

$50 \mathrm{ug} / \mathrm{kg}$ G-CSF or PBS

\section{Cocaine}

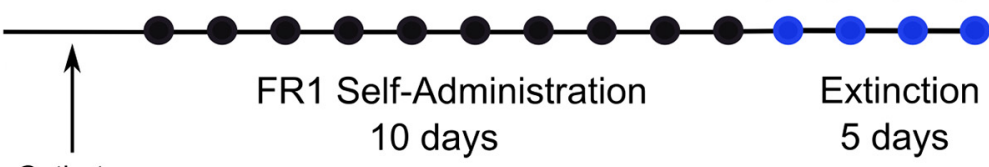

Catheter surgery

\section{B: Acquisition}

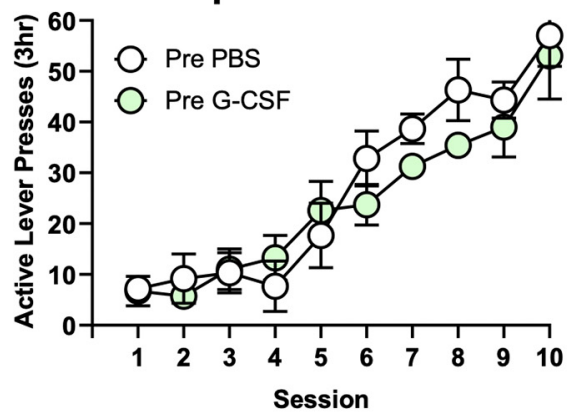

\section{D: Extinction}

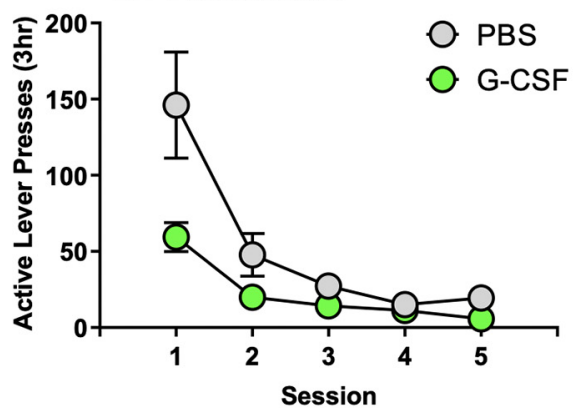

C: Inactive Presses Acq

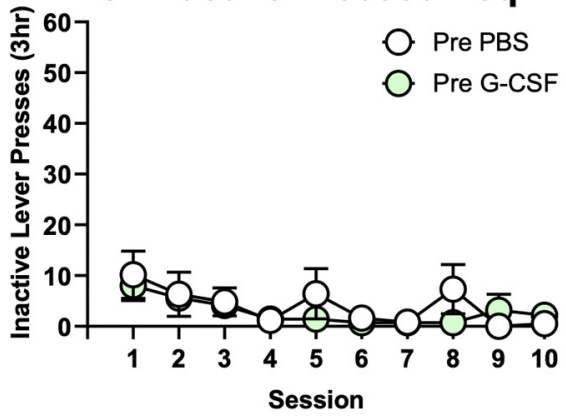

E: Inactive Presses Ext

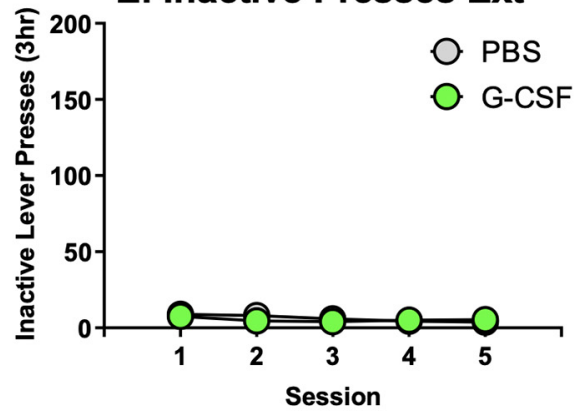

F: Locomotor Activity

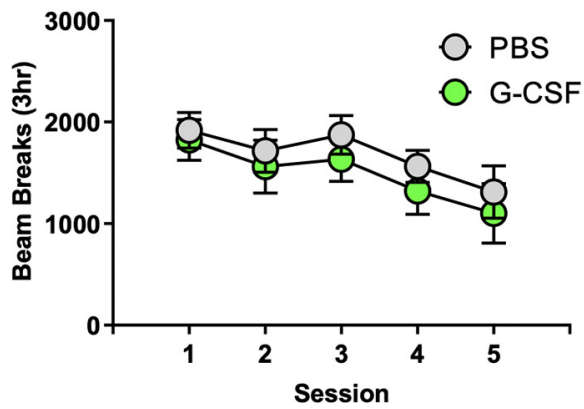

Figure 1. G-CSF treatment accelerates extinction. $\boldsymbol{A}$, Schematic for experiment 1. $\boldsymbol{B}$, Acquisition of active responding for cocaine (0.8 $\mathrm{mg} / \mathrm{kg} / \mathrm{infusion}$, FR1) for rats later assigned to PBS or G-CSF groups showed no group differences $\left(F_{(1,11)}=0.79, p>0.05\right)$. C, Pretreatment groups also did not differ on inactive lever presses $\left(F_{(1,11)}=0.48, p>0.05\right)$. $\boldsymbol{D}$, During extinction injections of G-CSF reduced lever pressing on the previously active lever $\left(F_{(1,11)}=5.37, p<0.05\right)$ but did not affect rates of inactive lever pressing $\left(\boldsymbol{E}, F_{(1,11)}=0.10, p>0.05\right)$. $\boldsymbol{F}$, Locomotor data during extinction show no effect of $\mathrm{G}$-CSF on general activity $\left(F_{(1,11)}=0.32, p=0.58\right)$. All data presented as means \pm SEM, $* p<0.05$, main treatment effect.

Corporation) connected to an Orbitrap Fusion Tribrid (ThermoFisher Scientific) mass spectrometer. After injection, the samples were loaded into a trapping column (nanoACQUITY UPLC Symmetry C18 Trap column, $180 \mu \mathrm{m} \times 20 \mathrm{~mm}$ ) at a flow rate of $5 \mu \mathrm{l} / \mathrm{min}$ and separated with a C18 column (nanoACQUITY column Peptide BEH C18, $75 \mu \mathrm{m} \times 250$ $\mathrm{mm})$. The compositions of mobile phases $\mathrm{A}$ and $\mathrm{B}$ were $0.1 \%$ formic acid in water and $0.1 \%$ formic acid in $\mathrm{ACN}$, respectively. The peptides were eluted with a gradient extending from $6 \%$ to $35 \%$ mobile phase B in $90 \mathrm{~min}$ and then to $85 \%$ mobile phase B in additional $15 \mathrm{~min}$ at a flow rate of $300 \mathrm{nl} / \mathrm{min}$ and a column temperature of $37^{\circ} \mathrm{C}$. The data were acquired with the mass spectrometer operating in targeted mode with a $\mathrm{MS}^{2}$ isolation window of $1.6 \mathrm{~m} / \mathrm{z}$. The full scan was performed in the 


\section{A: Experiment 2 Timeline}

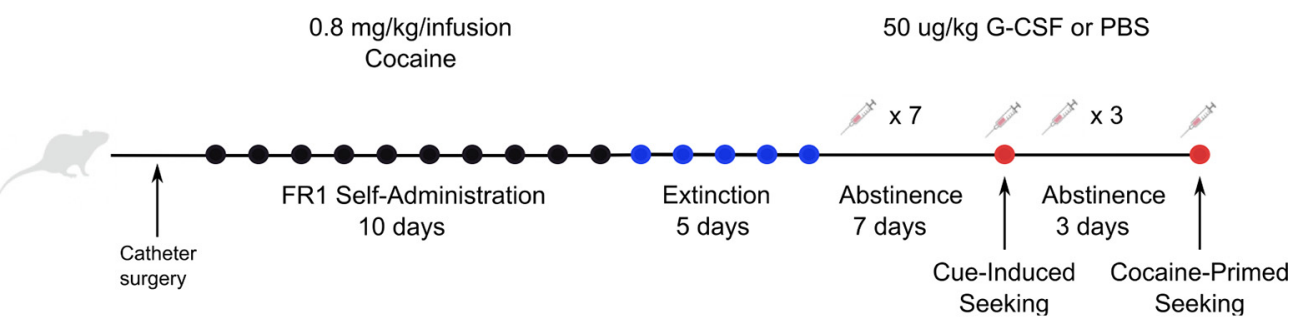

B: Acquisition

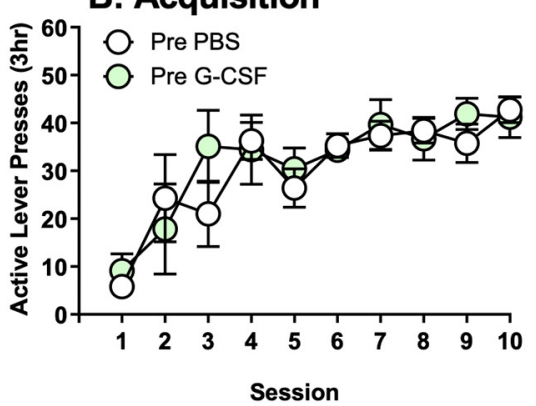

D: Extinction

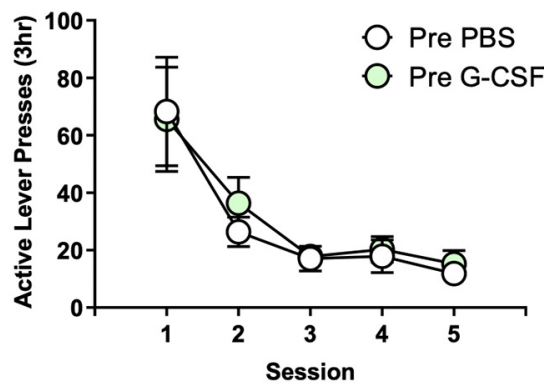

C: Inactive Lever Presses Acq

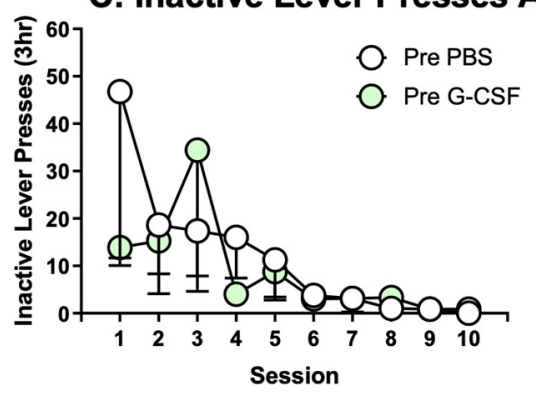

E: Inactive Lever Presses Ext

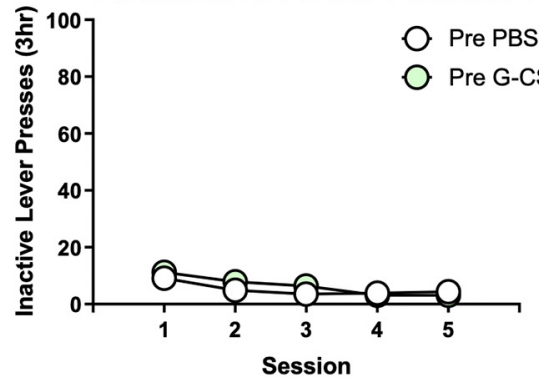

Cocaine-Seeking Tests
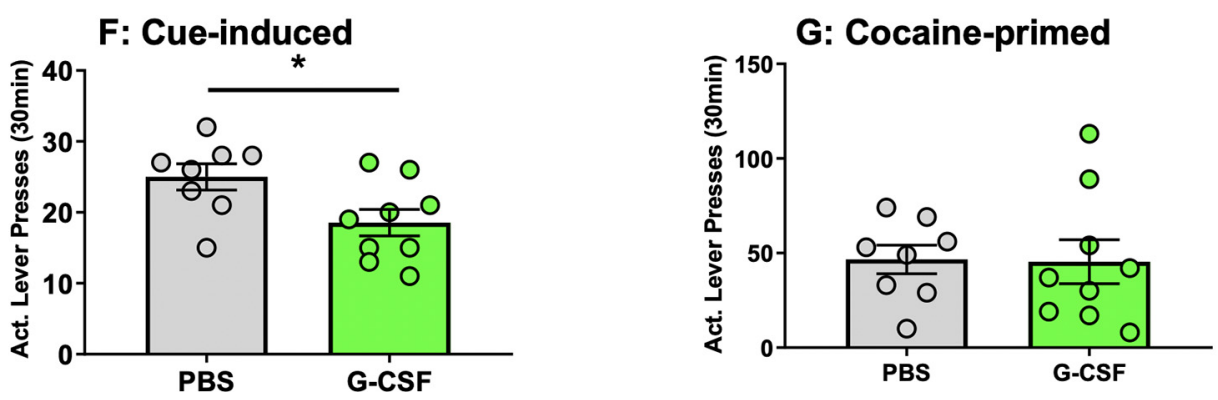

Figure 2. G-CSF reduces cue-primed but not cocaine-primed drug seeking when administered during abstinence. $\boldsymbol{A}$, Schematic for experiment 2. B, Rats later assigned to PBS or G-CSF groups did not differ in their active or $(C)$ inactive pressing during acquisition of cocaine self-administration $(0.8 \mathrm{mg} / \mathrm{kg} / \mathrm{infusion}$, FR1), but there was a main effect of session on active lever pressing $\left(F_{(3.84,52.86)}=8.77, p<0.0001\right)$. Additionally, pretreatment groups did not differ in active $(\boldsymbol{D})$ lever pressing or $(\boldsymbol{E})$ inactive lever presses during extinction, but there was a main effect of session on previously active lever pressing $\left(F_{(1.13,13.53)}=15.77, p<0.01\right)$. $\boldsymbol{F}$, G-CSF treatment during abstinence reduced responding for cue-induced drug seeking $\left(t_{(15)}=2.45, p<0.05\right)$. However, there was no effect during cocaine-primed seeking $\left(G, t_{(15)}=0.08, p>0.05\right)$. All data presented as means $\pm \mathrm{SEM} ; * p<0.05$, main treatment effect.

range of $350-1200 \mathrm{~m} / \mathrm{z}$ with use quadrupole isolation enabled at an Orbitrap resolution of 120,000 at $200 \mathrm{~m} / \mathrm{z}$ and AGC target value of $4 \times 105$. The $\mathrm{MS}^{2}$ scan range was set to $100-2000 \mathrm{~m} / \mathrm{z}$. Fragment ions from each peptide $\mathrm{MS}^{2}$ were generated in the C-trap with HCD at a collision energy of $28 \%$ and were detected in the Orbitrap at a resolution of 60,000 . Spectra for each peptide was generated within a 6-min time window defined by an inclusion list.
PRM spectra were then analyzed by Skyline-daily software v. 20.1.9.234 (MacCoss Lab, University of Washington). The spectra were searched against a fractionated spectral library from rat brain tissue with a library dot product minimum of 0.8 . The top six transition ion peak area intensities were integrated and summed for each peptide. Protein quantitation values were then calculated by averaging the peptide quantitative values. One sample from the G-CSF treatment group 
was markedly different from both G-CSF and PBS treatment groups on principal component analysis of total results and was thus excluded from analysis on all proteins.

Experimental design and statistical analyses

For self-administration and extinction, data were analyzed separately using linear mixed effects with group (PBS or G-CSF) as a between-subjects fixed factor, session as a within-subject fixed factor, and subject as a random factor. Significant interactions were probed with post hoc analyses using HolmSidak. Lever pressing during cue-primed and cocaine-primed seeking were analyzed using independent samples $t$ tests. Greenhouse-Geisser correction was applied when appropriate. Cumulative frequency curves of cue-primed and cocaine-primed seeking lever pressing over time were analyzed by independent samples $t$ tests of area under the curve between PBS treated and GCSF-treated rats during the first $3 \mathrm{~min}$ and the last $3 \mathrm{~min}$. For discovery proteomics, two-tailed $t$ tests between PBS-treated and G-CSF-treated raw intensity values were conducted using Scaffold DIA software, significance was determined using an uncorrected $p<0.05$. For confirmatory proteomics analyses, two-way ANOVA analyses were conducted separately on DIA (discovery) and PRM (confirmatory) datasets compared with PBS controls to identify main effect of G-CSF in each analysis. Planned pairwise comparisons for confirmatory proteomics were performed using one-tailed $t$ tests.

\section{Results}

Experiment 1: G-CSF facilitates extinction of cocaine selfadministration

Previous studies implicate G-CSF in enhancing cognitive flexibility on a reversal learning task (Kutlu et al., 2018). Given its ability to enhance motivated learning, we postulated that administration of G-CSF during extinction might hasten extinction learning. Rats were trained to self-administer cocaine and were split into two equally administering groups that would then be treated with G-CSF or PBS (Fig. 1A). No group differences in active $\left(F_{(1,11)}=0.79\right.$, $p=0.39$; Fig. $1 B)$ or inactive $\left(F_{(1,11)}=0.48, p=0.50\right.$; Fig. $\left.1 C\right)$ lever pressing was found between rats that were later assigned into the PBS or G-CSF groups. As expected, only a main effect of session was found for active lever presses $\left(F_{(9,97)}=33.52, p<0.0001\right.$; Fig. $\left.1 B\right)$ and inactive lever presses $\left(F_{(9,95)}=2.95, p=0.004\right.$; Fig. $\left.1 C\right)$ during acquisition, with no significant treatment $\times$ session interactions for active lever presses $\left(F_{(9,97)}=0.93, p=0.50\right)$ or inactive lever presses $\left(F_{(9,95)}=0.85, p=0.58\right)$. However, during extinction, rats treated with G-CSF showed decreased responding on the previously active lever beginning on the first day of extinction (Fig. 1D). Throughout the sessions there was a main effect of treatment $F_{(1,11)}=5.37$, $p=0.04$, as well as session $F_{(1.2,11.13)}=23.4, p=0.0003$, and a significant treatment $\times$ session interaction $F_{(4,37)}=4.63, p=0.0039$. However, post hoc analysis comparing G-CSF-treated and PBStreated active lever presses on each day did not yield any significant individual day effects (Fig. 1D). Importantly, treatment with G-CSF did not lead to any changes in responding on the inactive lever $\left(F_{(1,11)}=0.10, p=0.76\right.$; Fig. $\left.1 E\right)$ and there was also no effect of session $\left(F_{(2.21,20.39)}=2.68, p=0.09\right)$ and no interaction $\left(F_{(4,37)}=0.62\right.$, $p=0.65)$ on inactive lever presses during extinction. Additionally, to test whether reduced extinction responding was because of a decrease in activity, we monitored locomotor activity within the operant chamber across days, and this was also not affected by treatment with G-CSF (group effect: $F_{(1,11)}=0.32, p=0.58$; session effect: $F_{(2.25,20.77)}=$ $6.60, p=0.0048$; interaction: $F_{(4,37)}=0.31, p=0.87$; Fig. $\left.1 F\right)$.

Experiment 2: G-CSF attenuates cue- but not cocaine-primed seeking

Given that G-CSF attenuated extinction responding beginning on the first day of training, we next investigated whether G-CSF treatment during abstinence could reduce drug seeking. For experiment 2, a different set of animals were trained to self-
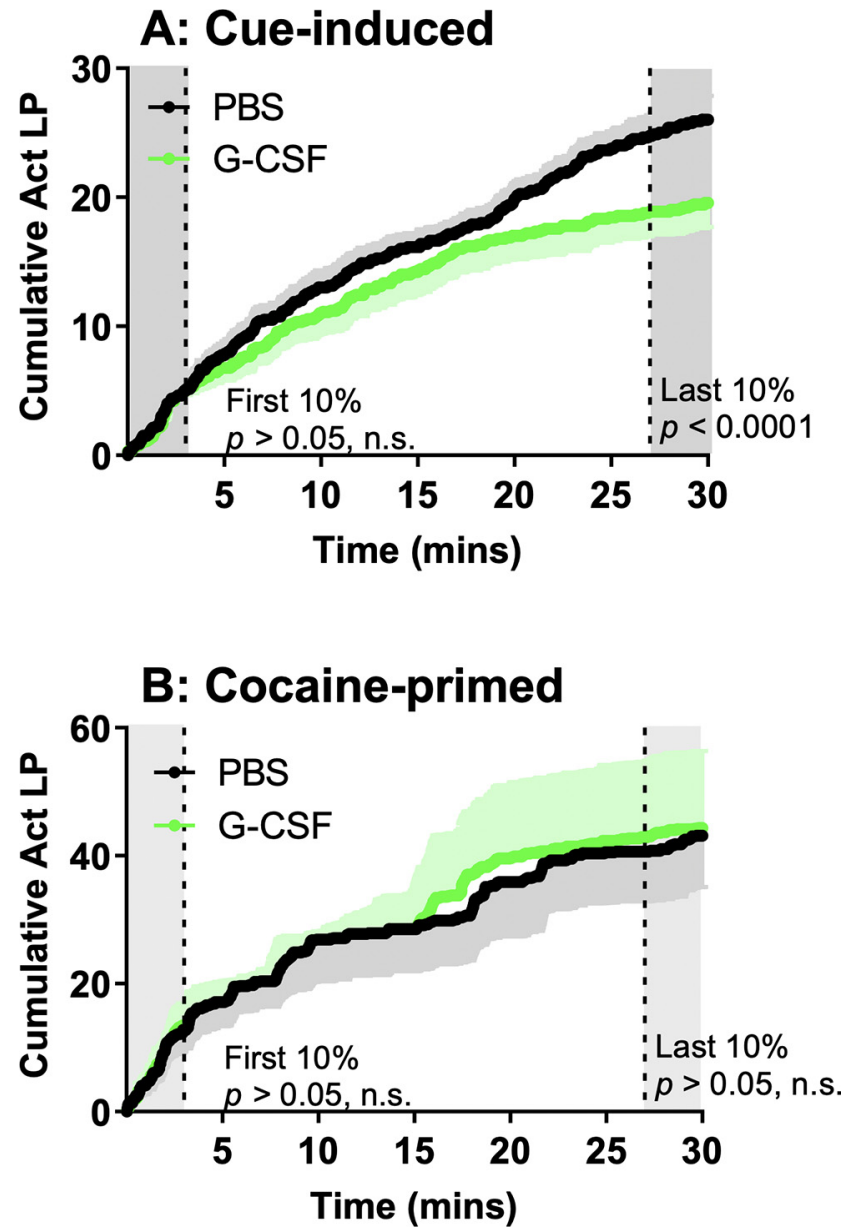

Figure 3. G-CSF treatment leads to updated response output over the course of cueinduced seeking session. $\boldsymbol{A}$, G-CSF-treated and PBS-treated rats did not differ in lever pressing within the first $10 \%$ of the cue-induced reinstatement session $\left(t_{(15)}=1.79, p>0.05\right)$, but significantly differed during the final $10 \%$ of the session $\left(t_{(15)}=16.25, p<0.0001\right)$. $B, G$-CSF-treated and PBS-treated rats did not differ in the first $10 \%$ of their cocaine-primed reinstatement session nor the final 10\% (first 10\%: $t_{(15)}=0.01, p>0.05$; final $10 \%: t_{(15)}=$ $0.92, p>0.05)$. Black lines $=$ PBS, green lines $=\mathrm{G}-\mathrm{CSF}$, black and green shading colors above and below indicate SEM.

administer cocaine on an FR1 schedule and then underwent $5 \mathrm{~d}$ of extinction before any treatments (Fig. $2 A$ ). Animals were divided into groups with equal levels of self-administration and inactive lever presses during the acquisition phase (active lever press treatment effect: $F_{(1,15)}=0.21, p=0.66$, active lever press session effect: $F_{(3.84,52.86)}=8.77, p<0.0001$, active lever interaction: $F_{(9,124)}=0.69, p=0.72$ and inactive lever press treatment effect: $F_{(1,15)}=0.25, p=0.63$, inactive lever press session effect: $F_{(2.38,35.10)}=1.88, p=0.16$, and inactive lever press interaction: $F_{(9,133)}=0.65, p=0.75$; Fig. $\left.2 B, C\right)$, as well as with equal responding on previously active and inactive levers during the extinction phase of training (formerly active lever presses treatment effect: $F_{(1,15)}=0.15, p=0.70$, formerly active lever presses session effect: $F_{(1.13,13.53)}=15.77, p=0.0011$, formerly active lever interaction: $F_{(4,48)}=0.195, p=0.94$ and inactive lever press treatment effect: $F_{(1,15)}=0.83, p=0.38$, inactive lever press session effect: $F_{(2.24,26.84)}=8.37, p=0.0011$, inactive lever press interaction: $F_{(4,48)}=0.90, p=0.47$; Fig. $\left.2 D, E\right)$. When drug seeking was measured, daily injections of G-CSF during abstinence significantly attenuated cue-induced seeking $\left(t_{(15)}=2.45\right.$, $p=0.027$; Fig. $2 F$ ). When cocaine-primed seeking was assessed after three more days of abstinence and G-CSF injections, there 


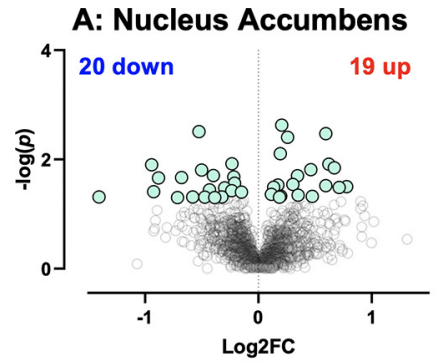

\section{D: Dorsal mPFC}

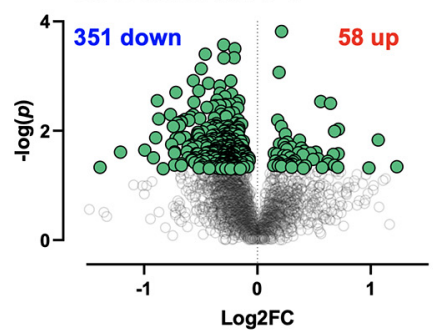

B: Downregulated NAC

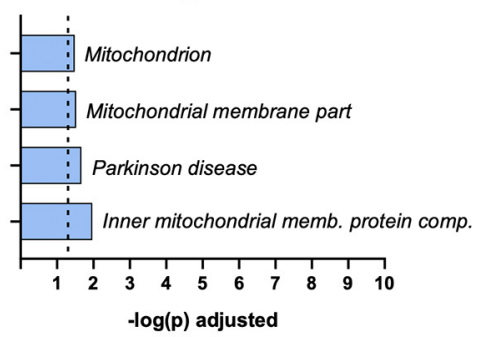

E: Downregulated mPFC

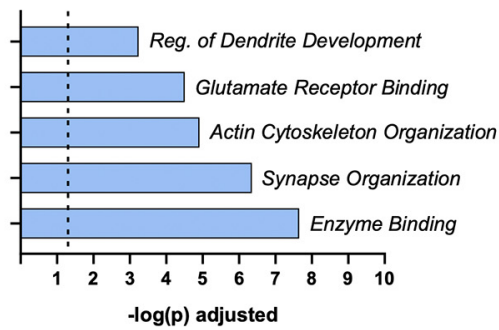

\section{C: Upregulated NAC}

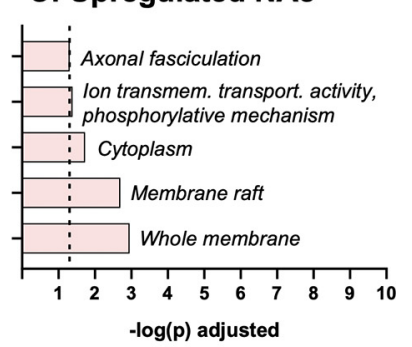

F: Upregulated mPFC

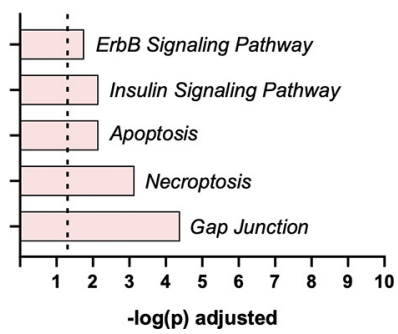

Figure 4. Proteomic effects of G-CSF on NAc and dorsal mPFC. A, Volcano plot depicting differential protein expression in the NAc between rats treated with G-CSF compared with PBS controls. Extended Data Figure 4-1 lists all regulated proteins in the NAc with statistics. $B$, C, Significantly altered pathways in NAc identified from G:Profiler using significantly downregulated and upregulated inputs. Extended Data Figure 4-2 has details of significant ontologies. D, Volcano plot depicting differential protein expression between rats treated with G-CSF compared with PBS in mPFC. Extended Data Figure 4-3 lists all regulated proteins in the mPFC with statistics. $E$, $\boldsymbol{F}$, Significantly altered pathways in mPFC identified from G:Profiler using significantly downregulated and upregulated inputs. Extended Data Figure 4-4 lists details of significant ontologies.

was no effect of G-CSF $\left(t_{(15)}=0.08, p=0.94\right.$; Fig. $\left.2 G\right)$. G-CSF did not affect inactive lever presses during either cue $\left(t_{(15)}=\right.$ $0.11, p=0.92)$ or cocaine-primed seeking tests $\left(t_{(15)}=0.76\right.$, $p=0.46$; data not shown).

G-CSF reduces lever pressing late versus early within the cueinduced reinstatement session

Our previously published data on reversal learning (Kutlu et al., 2018) and the current data from the extinction and reinstatement experiments all suggested that G-CSF might be enhancing the ability of animals to rapidly update their response contingencies. To examine this in more detail, we analyzed cumulative responding on the previously active lever within each drug-seeking session. As shown in Figure 2F, G-CSF-treated rats pressed the previously active lever less than control rats. However, within the first $10 \%$ (3 min) of the session, there was no difference in cumulative active lever presses between groups as assessed by comparison of area under the curve $\left(t_{(15)}=1.79, p=0.09\right.$; Fig. $3 A$ ) indicating that G-CSF rats are sampling the active lever at the same rate as controls early in the session. However, by the last $10 \%$ of the session the G-CSF treated animals have decreased pressing on the previously active lever to levels below those of the control animals $\left(t_{(15)}=16.27, p<0.0001\right)$. This suggests that increased levels of G-CSF might lead to rapid adjustment of behavior in response to altered reward availability over the course of a single session. In contrast, G-CSF did not significantly affect the rate of responding across a cocaine-primed seeking session (first $10 \%$ : $t_{(15)}=0.01, p=0.99$; final $10 \%$ : $t_{(15)}=0.92$, $p=0.37$; Fig. $3 B$ ).

G-CSF given during abstinence alters the proteomic landscape of the mPFC but only minimally affects protein expression in the NAc

While evidence suggests that G-CSF alters dopamine dynamics in the NAc (Kutlu et al., 2018; Brady et al., 2019), the full mechanisms by which it alters behavioral plasticity are currently unknown. To gain insight into the neural processes underlying the effect of G-CSF on attenuated cocaine-seeking, a DIA discovery proteomic analysis was performed on two areas of the corticolimbic reward circuit in G-CSF-treated and PBS-treated rats from experiment 2 . This method allows for unbiased detection of quantitative differences between treatment groups with improved coverage of the proteome compared with more conventional data dependent acquisition methods (Wilson et al., 2019). Both NAc and dorsal mPFC from rats administered G-CSF or PBS during abstinence (experiment 2) underwent proteomic analysis. G-CSF treatment resulted in differential expression of 39 proteins in NAc (20 upregulated and 19 downregulated; Fig. 4A; Extended Data Fig. 4-1). Upregulated and downregulated proteins were clustered into groups based on their function or their location in a cell using GO or the KEGG pathway analysis. For differentially regulated proteins in NAc, pathway analysis identified very few significant ontologies, with membrane rafts and membrane proteins being the most significant pathways (Fig. 4B,C; Extended Data Fig. 4-2). In contrast, analysis of G-CSF effects in the $\mathrm{mPFC}$ led to robust regulation of many proteins with 351 downregulated and 58 upregulated (Fig. 4D; Extended Data Fig. 4-3). Pathway analysis of these proteins showed numerous strongly significantly enriched pathways, most notably with those related to glutamate receptors, synapse organization, and enzyme binding in the decreased proteins (Fig. 4E,F; Extended Data Fig. 4-4).

Given the discrepancy in the number of proteins that were altered by G-CSF treatment during abstinence in the two brain regions, we also performed comparison analysis to see whether this was an effect of magnitude of protein change, or whether the cytokine treatment was indeed altering different pathways between the two regions. In Figure 5, we outline the most significantly altered pathways in each 


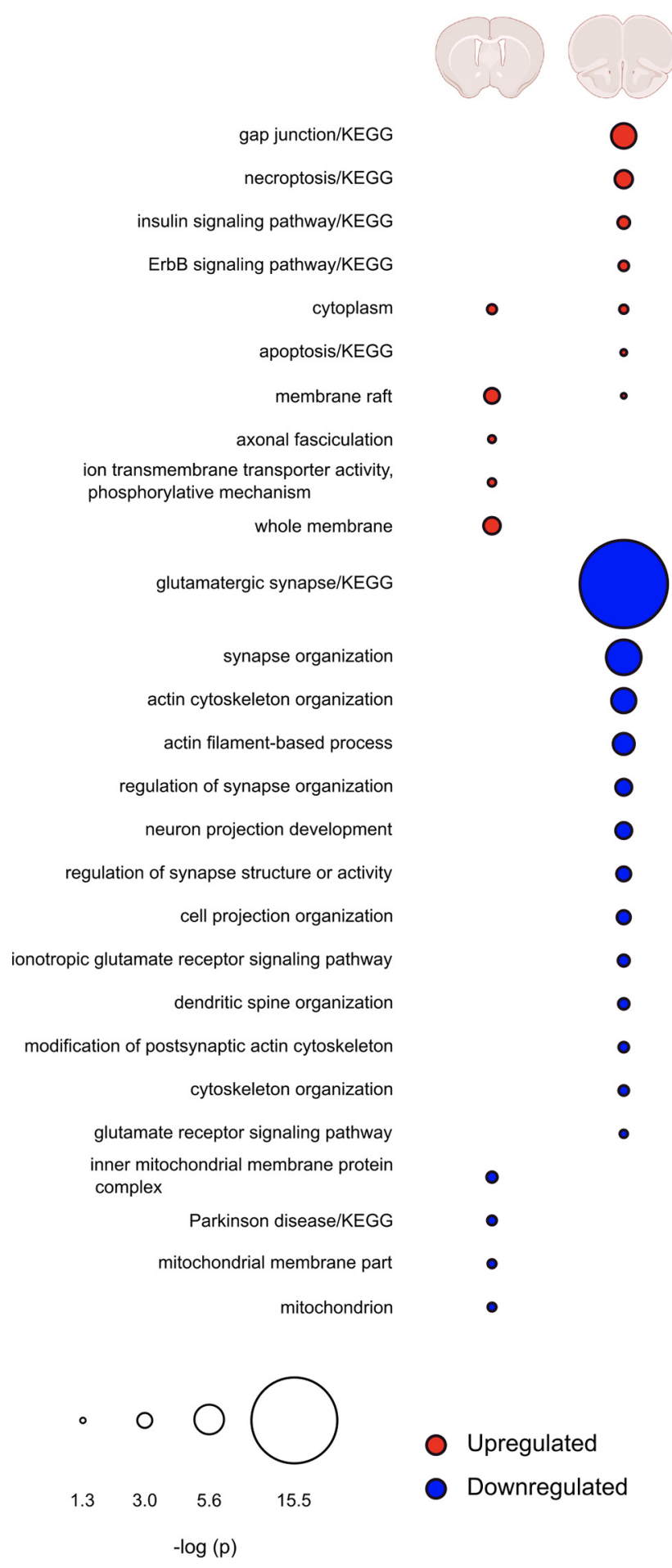

Figure 5. Comparison of regulated pathways in $\mathrm{mPFC}$ and NAc after G-CSF treatment. Overlap of pathways found to be significantly enriched by G-CSF treatment in NAc (left) or mPFC (right). Upregulated pathways are indicated in red, downregulated in blue. Radius of circles is the FDR-corrected $-\log p$ value of that pathway. Blank spaces for either brain region indicate no proteins from that pathway were significantly regulated by G-CSF in that region.

brain region and show overlap between the two. As is clearly seen, the regulation of proteins in the two brain regions is largely distinct other than some overlap in upregulated cytoplasmic proteins. These findings suggest that G-CSF during abstinence is having markedly different effects on the mPFC and NAc.

\section{G-CSF treatment during abstinence downregulates}

cytoskeleton, synapse formation, and glutamatergic signaling pathways in $\mathrm{mPFC}$

To further interrogate the functional consequences of G-CSF treatment we performed STRING analysis to identify predicted PPIs among proteins altered by G-CSF treatment. Proteins downregulated by G-CSF in the mPFC form a densely interconnected network with 933 predicted PPIs which is significantly greater than the 550 that would be expected by chance $(p<1 \times$ $10^{-16}$; Fig. $6 A$ ). Within this primary network there was an average of 5.44 interactions predicted per regulated protein. The upregulated proteins from $\mathrm{mPFC}$, which were less abundant than those downregulated, also had significantly higher protein interactions than predicted by chance ( 36 edges, $p=0.0008$, average node degree 1.26). However, differentially regulated proteins from NAc did not have significant increases in predicted interactions, again suggesting that the effects of G-CSF during abstinence seem to be driven by changes in mPFC. Full STRING statistics are available as Extended Data Figure 6-1.

Within the downregulated mPFC proteins, we performed additional analyses on some of the most significantly regulated pathways related to synaptic function. Proteins involved in glutamatergic signaling were highly downregulated and create a densely interactive protein network (Fig. $6 B$ ). The same is true for proteins known to play key roles in regulation of the actin cytoskeleton (Fig. 6C) and synapse development (Fig. 6D). All of these pathways are critical for formation of appropriate structural and synaptic plasticity, and all form densely interconnected networks significantly above chance levels $\left(p<1 \times 10^{-16}\right.$ for all three). Notable proteins occurring in glutamate pathways were GluN2B (NMDE2), mGluR5 (GRM5), GluN1 (NMDZ1), CaMKI (KCC1A), and Shank2 (SHAN2), while the interesting proteins Shank1 (SHAN1), Dnm3 (DYN3), and Kalrn appeared in synapse organization, actin cytoskeleton, and glutamate pathways. A merged version of these three networks is presented as Figure 7 and shows how the proteins downregulated by G-CSF lead to decreases in signaling cascades involved in formation and potentiation of synapses in this critical brain region.

\section{Confirmation of proteomics findings with targeted proteomics analysis}

Results from the DIA discovery proteomics analysis revealed that G-CSF affected protein networks related to synaptic plasticity specifically in the PFC. However, given the exploratory nature of these experiments, we next performed confirmatory proteomics analysis on key proteins that were regulated in these analyses. To achieve this, we used PRM in which spectra from predetermined peptides were targeted for quantitative analysis. Using the proteins seen to be downregulated in Figure 7, we selected targets with at least two individual peptides that could be detected with high levels of sensitivity and specificity (selected peptides listed in Extended Data Fig. 8-1). For each selected protein we identified at least two unique peptides, and then analyzed the merged averages of these to provide an accurate estimate of whole protein quantification. In Figure $8 A$, we demonstrate the three individual peptides quantified from NMDE2 which each show a decrease in the G-CSF group and have a main effect of G-CSF by two-way $\operatorname{ANOVA}\left(F_{(1,18)}=19.73 ; p=0.0003\right)$. As is convention for these PRM analyses the values for each peptide were averaged and then compared between groups which again shows a significant effect of G-CSF treatment $\left(t_{(6)}=3.31 ; p=0.008\right)$. In Figure $8 B$, we show SHANK2 as an example of a protein quantified 


\section{A: All downregulated proteins - mPFC}

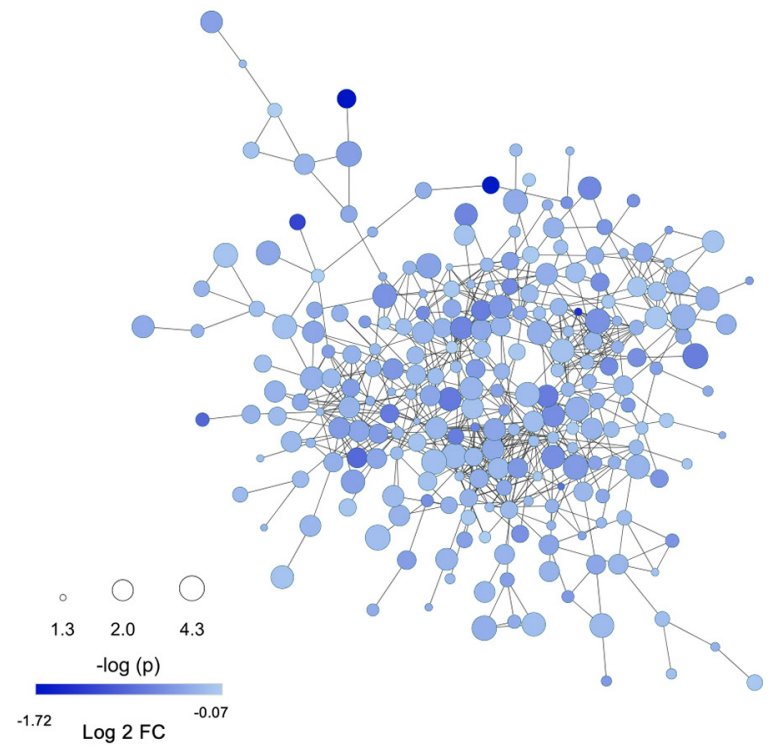

\section{B: Glutamatergic synapse}

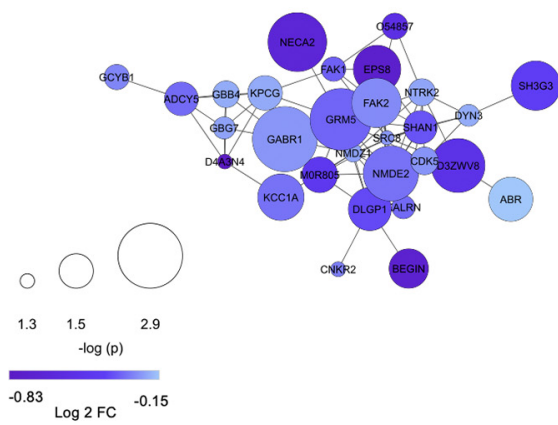

\section{C: Synapse Development}

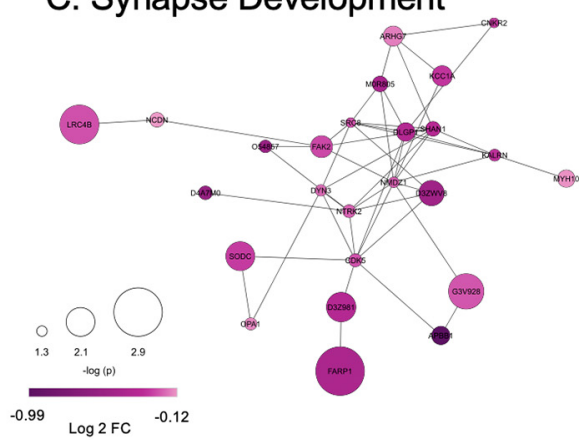

\section{D: Actin Cytoskeleton}

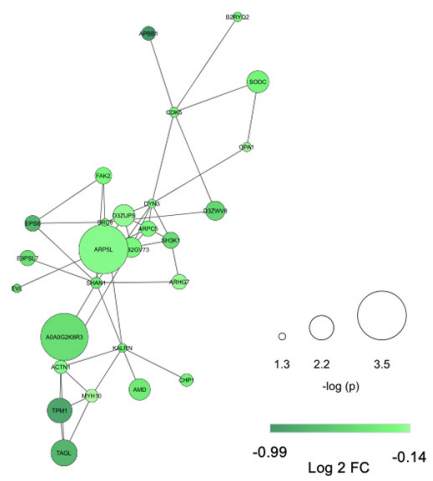

Figure 6. Downregulated proteins in the mPFC are from densely interactive networks with enrichment for synapses. A, STRING protein interaction diagram of all proteins significantly downregulated by G-CSF in mPFC. Enrichment of interacting proteins is strongly statistically significant $\left(p<1.0 \times 10^{-16}\right)$ with an average number of 5.44 interactions per protein. Selected pathways were isolated from G:Profiler analyses to highlight interactions among downregulated proteins related to glutamatergic pathways $(\boldsymbol{B})$, regulation of synapse development $(\boldsymbol{C})$, and actin cytoskeleton-related pathways $(\boldsymbol{D})$, all of which have significantly more PPIs than would be predicted by chance $\left(p<1.0 \times 10^{-16}\right.$ for all). Protein nodes differ by size (-log $p$ value, larger node $=$ smaller $p$ value) and color (darker color $=$ greater fold change from PBS). Extended Data Figure 6-1 details STRING connectivity analysis for each network. Extended Data Figure $6-2 B-D$ has detailed analysis of proteins identified.

from two peptides in which there is a main effect of G-CSF when examined individually $\left(F_{(1,12)}=8.948 ; p=0.011\right)$, and when averaged for protein quantification they again demonstrate an effect of G-CSF $\left(t_{(6)}=2.26 ; p=0.03\right)$.
To examine how the effects of these confirmatory proteomics replicate our original discovery proteomics we performed twoway ANOVA analysis of these proteins relative to controls for each method. For the original discovery proteomics analysis, 


\section{Merged Glutamate, Cytoskeleton, and Synapse Pathways}

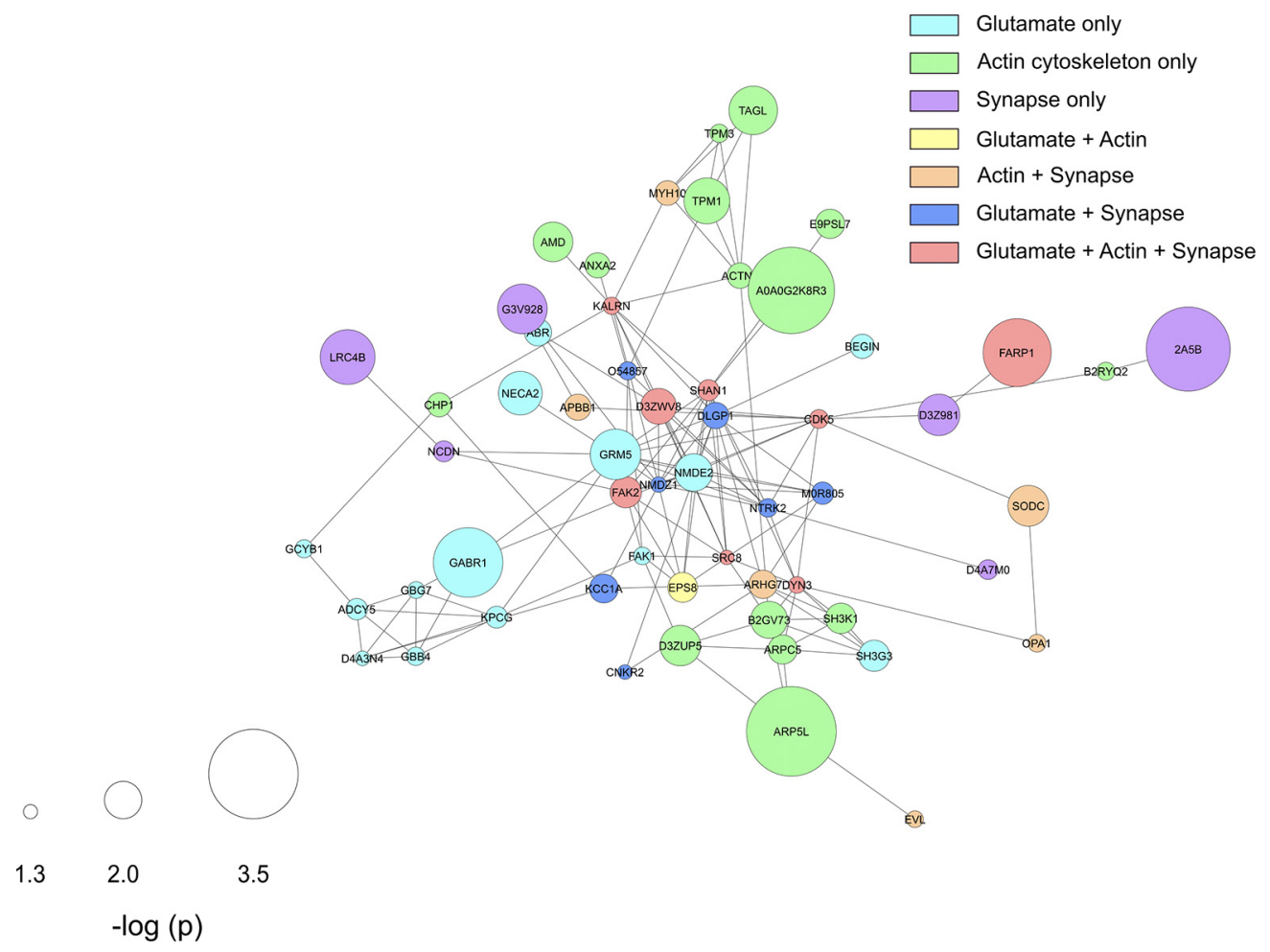

Figure 7. Overlap of synaptic and cytoskeletal protein interactions in the MPFC. Using the regulated proteins from glutamate, synaptic, and cytoskeletal pathways, a STRING diagram was created showing the effect of G-CSF treatment on these critical regulators of synaptic plasticity and function. This network has 138 predicted PPIs compared with the 29 that would be predicted by chance (PPI $p$ value $<1.0 \times 10^{-16}$; average node degree 3.83). Node color indicates pathway membership as shown in legend. Node size correlates with -log $p$ value compared with PBS control.

there was a main effect of G-CSF in these proteins $\left(F_{(1,105)}=\right.$ $123.2, p<0.0001$; Fig. $8 C$, left). When the same proteins were analyzed in our confirmatory PRM analyses all proteins had a mean decrease in the same direction as the discovery analysis (Fig. $8 C$, right) and there was a main effect of G-CSF treatment of similar magnitude to the original discovery analysis $\left(F_{(1,90)}=\right.$ 57.42; $p<0.0001)$. Individual comparisons for each protein are indicated by asterisks on the graph and detailed comparisons are provided as Extended Data Figure 8-2.

\section{Discussion}

The current set of studies demonstrate that G-CSF administration accelerates extinction and reduces cue-induced cocaineseeking (Figs. 1, 2). While this seems contrary to the effects of GCSF in potentiating effects on cocaine reward and self-administration (Calipari et al., 2018), there is a fair amount of evidence showing that G-CSF enhances learning in many different forms (Diederich et al., 2009a,b; Kutlu et al., 2018). Integrating past findings with our current results, it seems G-CSF may be speeding response-outcome learning when administered during self-administration, and speeding learning when given during extinction or abstinence. Since extinction learning is a form of behavioral flexibility (Hamilton and Brigman, 2015), this study is also in line with Kutlu et al. (2018), demonstrating that G-CSF reduces trials to criterion in a reversal task. Interestingly, G-CSF did not influence cocaine-primed seeking. Caution is warranted when interpreting these results since cocaine-primed seeking always followed cue-induced seeking by $4 \mathrm{~d}$ and there were no intervening extinction sessions between cue-primed and cocaine-primed seeking tests. However, discrepancies between cue-primed and cocaine-primed seeking could be because of recruitment of unique albeit overlapping brain circuits (Kalivas and McFarland, 2003; Farrell et al., 2018) or it is possible that the injection of cocaine used for the prime might have interfered with any G-CSF influenced learning process. Future studies can test cocaine-primed seeking before cue-induced seeking to determine whether order of seeking tests helps explain these results.

This study also utilizes an unbiased approach to gain insight into the molecular consequences of G-CSF administration during abstinence that may underlie reduced cocaine seeking. Proteomics analyses show that G-CSF causes significant changes in expression of $\sim 400$ proteins in dorsal mPFC (Fig. $4 D$ ) but has less robust effects on protein expression in the NAc $(\sim 40$ proteins; Fig. 4A). We chose to examine these two brain regions as both the mPFC and NAc are necessary for cue-induced reinstatement (Koya et al., 2009; Stefanik et al., 2013). Pathway analysis of the $\mathrm{mPFC}$ demonstrates significant changes in proteins related to glutamatergic signaling and synapse formation. Some examples of proteins downregulated include the scaffolding proteins Shank1 and Shank2, NMDA receptor subunits GluN1 and GluN2B, as well as mGluR5 and CaMKI (Fig. 6; Extended Data Fig. 6-2). Confirmatory proteomics analyses using PRM showed that all proteins identified in our discovery analysis showed a mean change in the same direction on confirmatory analysis with a robust main effect of G-CSF in both (Fig. 8). It is important to note that brain tissue used for these analyses were taken after animals had undergone two cocaine 
A NMDE2 PRM Analysis

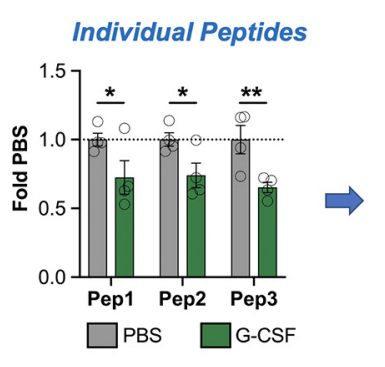

Mean Fold Control

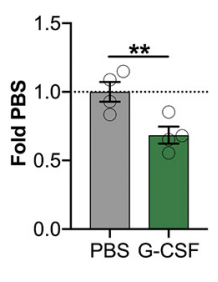

\section{B SHANK2 PRM Analysis}

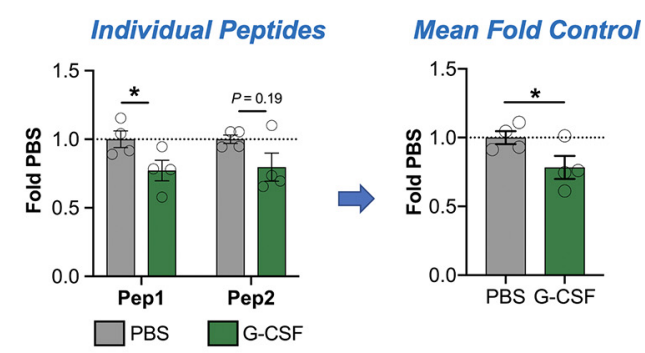

C

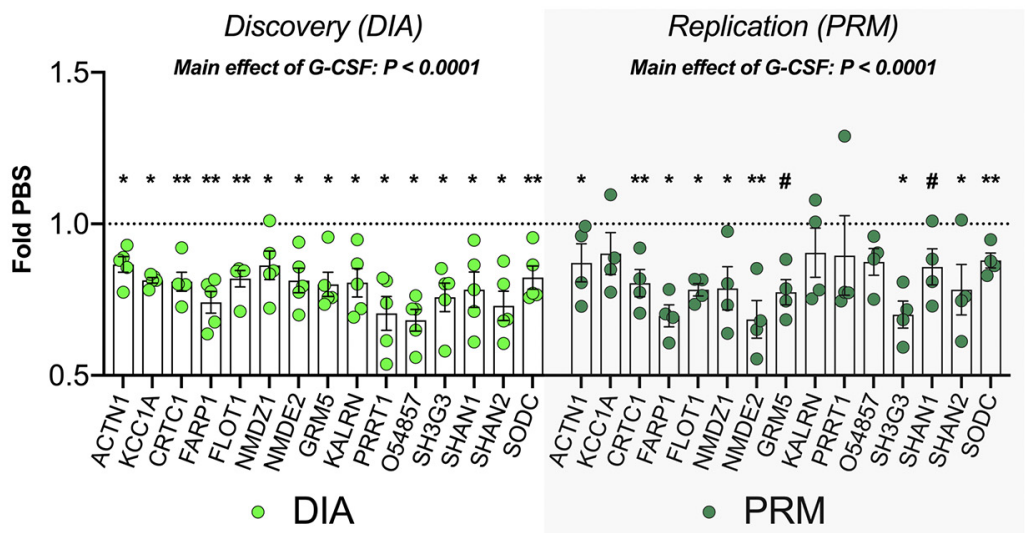

Figure 8. Replication of discovery proteomics analysis with PRM analysis. To ensure the validity of our initial DIA discovery proteomics analysis, a subset of key proteins was validated using targeted proteomics. $A$, As an example of a targeted protein with three analyzed peptides, data for NMDE2 are presented. On the left, the individual data for each peptide are shown, and then these values were averaged to quantify total protein change. B, SHANK2 is shown as an example in which two peptides were merged from a protein. $\boldsymbol{C}$, Data from the discovery DIA analysis (left) are shown in comparison to replication (right), and levels of each protein are changed in the same direction with both methodologies, and there is a robust main effect of $\mathrm{G}$-CSF with both methods. All data presented as means \pm SEM, $* p<0.05, * * p<0.01, \# p<0.1$ (replication only). Peptides analyzed from each protein are available in Extended Data Figure 8-1, and detailed statistics from both methods are presented in Extended Data Figure 8-2.

seeking tests and all rats received a non-contingent injection of cocaine $1 \mathrm{~h}$ before tissue collection. While it is unlikely that cocaine injection and cocaine-primed seeking caused massive downregulation of proteins in the G-CSF-treated rats in such a short period of time (Dörrbaum et al., 2018), the proteomic results are not purely reflecting changes in protein expression because of G-CSF alone, but are also influenced by rats' differential experience with the prior cue-induced seeking test.

Previous work has shown that pharmacological reduction of extracellular glutamate within the prelimbic cortex attenuates cocaine-seeking (Shin et al., 2018), highlighting the role of glutamate within this region in cue-induced reinstatement. Notably, the concomitant decreases in cue-induced drug seeking and GluN2B seen in our G-CSF-treated rats are in line with previous literature. GluN2B is upregulated in $\mathrm{mPFC}$ during abstinence from extended cocaine access (Ary and Szumlinski, 2007; BenShahar et al., 2009; Szumlinski et al., 2016) and inhibition of GluN2B-containing NMDA receptors in this area reduces cueinduced cocaine-seeking (Szumlinski et al., 2016). Additional work also confirms that mGluR5, another protein downregulated by G-CSF in the current dataset, is upregulated in dorsal mPFC 3 and $30 \mathrm{~d}$ after extended access cocaine self-administration (BenShahar et al., 2013), although the behavioral relevance (if any) of mGluR5 in dorsal mPFC is unclear. G-CSF administration during abstinence might prevent upregulation of glutamatergic synaptic proteins normally altered by cocaine withdrawal in the mPFC.

In models of disease, G-CSF has repeatedly been shown to attenuate glutamate excitotoxicity, specifically in models of stroke (Schäbitz et al., 2003; Han et al., 2008). G-CSF administration (either systemic or intrathecally), reduces extracellular levels of glutamate (Han et al., 2008; Chen et al., 2010) via multiple mechanisms and has been shown to downregulate glutamate receptors (Diederich et al., 2009b; Mammele et al., 2016), an effect recapitulated in the current study. The elevated levels of extracellular glutamate that are present in the MPFC during abstinence from cocaine self-administration (Shin et al., 2016) likely do not cause excitotoxicity; however, G-CSF-induced downregulation of glutamate synaptic proteins might be regulating excitatory synaptic strength. While more work is necessary, this raises the intriguing possibility that G-CSF might scale glutamate activity to balance synaptic plasticity necessary for learning with a reduction in excitotoxicity produced by those same pathways.

Given that our previous work found that the NAc was the brain region responsible for the effects of G-CSF on cocaine place preference (Calipari et al., 2018) and that G-CSF increased stimulated dopamine release in the NAc (Kutlu et al., 2018; Brady et al., 2019), the disparity of the effects of G-CSF in the mPFC and the NAc was not expected. However, both of these regions receive synaptic inputs from the VTA which is also affected by repeated G-CSF treatment (Mervosh et al., 2018). Additionally, in our original studies we found that treatment with G-CSF potentiated cocaine induced c-fos activation in both the mPFC and the NAc, suggesting G-CSF exerts effects in both brain regions (Calipari et al., 2018). The differential effects we see here could reflect the difference between administration of G-CSF during a period of active cocaine administration versus 
administration during abstinence, and may reflect the changes seen where G-CSF enhances cocaine intake during active administration (Calipari et al., 2018), but then hastens drug extinction and reduces cue-induced drug-seeking when given during abstinence. It is important to note the timeline of the current experiments. Most work on incubation of cocaine craving compare neurobiology of reinstatement circuits after short-term cocaine withdrawal ( 1 and $3 \mathrm{~d}$ ) to long-term or "incubated" cocaine withdrawal (28-30 d; Grimm et al., 2001; Conrad et al., 2008). It is at this longer time point when neural changes first appear, such as insertion of GluR2-lacking AMPA receptors into NAc (Conrad et al., 2008). Since the current study employed a combination extinction/abstinence protocol that resulted in cocaine withdrawal for $17 \mathrm{~d}$, it is possible that more protein changes would be observed in NAc at a later time point. In contrast with glutamatergic changes in the NAc, glutamatergic changes in $\mathrm{mPFC}$ occur quickly, with some effects appearing at $3 \mathrm{~d}$ (Huang et al., 2007) and most present by $14 \mathrm{~d}$ (Ben-Shahar et al., 2009).

Here, we employed an unbiased proteomic analysis using DIA to determine differences in protein expression between $\mathrm{G}$ CSF-treated and control-treated rats during abstinence. The use of this technique is important for two reasons. The first is that by using the DIA method, which bins proteins based on mass to charge $(\mathrm{m} / \mathrm{z}$ ) ratio (Wilson et al., 2019), we avoid the bias toward highly expressed proteins that is common with older data-dependent acquisition methods ( $\mathrm{Hu}$ et al., 2016) and achieve more complete coverage of the proteome. Within these analyses we detected with confidence 2604 proteins within NAc expressed in all samples and 3364 in mPFC expressed in all samples (for a list, see raw data in ProteomeXchange). The second is that by using proteomics we can directly assess the functional state of the cell using a proteome-wide approach. Most studies in the field have used some version of transcriptomics to assess the molecular state of a cell, and while these methods are incredibly powerful and have revolutionized the field, levels of transcript are only important if they are translated into protein. Given the extensive regulatory mechanisms on mRNAs, it would not be likely that there would be a strict 1:1 correlation of mRNA:protein (Payne, 2015), and indeed most studies that have examined these correlations find a correlation coefficient of $R^{2}=0.4$ or lower (Ghazalpour et al., 2011; Schwanhäusser et al., 2011; Kumar et al., 2016). Thus, by directly querying protein changes induced by G-CSF treatment we can draw greater inference of how these treatments are altering the functional state of the cell.

Recombinant G-CSF is FDA approved for the treatment of neutropenia and is well-tolerated with a favorable side effect profile (Hoggatt and Pelus, 2014). Additionally, G-CSF has been tested in clinical trials for multiple neurologic conditions including stroke and Alzheimer's disease, thus establishing the feasibility of using G-CSF as a therapeutic for a neuropsychiatric condition. This, along with the data presented herein, lay the foundation for a potential re-purposing of G-CSF for the treatment of SUDs. Importantly, this current work also identifies multiple protein targets for G-CSF's effects in the mPFC and hints at a largely glutamatergic mechanism of action in its ability to reduce cocaine-seeking. The tolerability of G-CSF and uncovering of its cellular targets can guide the search for effective pharmacological interventions for psychostimulant use disorder.

\section{References}

American Psychiatric Association (2013) Diagnostic and statistical manual of mental disorders, Ed 5. Arlington: American Psychiatric Association.
Ary AW, Szumlinski KK (2007) Regional differences in the effects of withdrawal from repeated cocaine upon Homer and glutamate receptor expression: a two-species comparison. Brain Res 1184:295-305.

Ben-Shahar O, Obara I, Ary AW, Ma N, Mangiardi MA, Medina RL, Szumlinski KK (2009) Extended daily access to cocaine results in distinct alterations in Homer $1 \mathrm{~b} / \mathrm{c}$ and NMDA receptor subunit expression within the medial prefrontal cortex. Synapse 63:598-609.

Ben-Shahar O, Sacramento AD, Miller BW, Webb SM, Wroten MG, Silva HE, Caruana AL, Gordon EJ, Ploense KL, Ditzhazy J, Kippin TE, Szumlinski KK (2013) Deficits in ventromedial prefrontal cortex group 1 metabotropic glutamate receptor function mediate resistance to extinction during protracted withdrawal from an extensive history of cocaine self-administration. J Neurosci 33:495-506a.

Brady LJ, Hofford RS, Tat J, Calipari E, Kiraly DD (2019) Granulocyte-colony stimulating factor alters the pharmacodynamic properties of cocaine in female mice. ACS Chem Neurosci 10:4213-4220.

Calipari ES, Godino A, Peck EG, Salery M, Mervosh NL, Landry JA, Russo SJ, Hurd YL, Nestler EJ, Kiraly DD (2018) Granulocyte-colony stimulating factor controls neural and behavioral plasticity in response to cocaine. Nat Commun 9:9.

Chen WF, Sung CS, Jean YH, Su TM, Wang HC, Ho JT, Huang SY, Lin CS, Wen $\mathrm{ZH}$ (2010) Suppressive effects of intrathecal granulocyte colonystimulating factor on excessive release of excitatory amino acids in the spinal cerebrospinal fluid of rats with cord ischemia: role of glutamate transporters. Neuroscience 165:1217-1232.

Conrad KL, Tseng KY, Uejima JL, Reimers JM, Heng L-J, Shaham Y, Marinelli M, Wolf ME (2008) Formation of accumbens GluR2-lacking AMPA receptors mediates incubation of cocaine craving. Nature 454:118-121.

Diederich K, Schäbitz WR, Kuhnert K, Hellström N, Sachser N, Schneider A, Kuhn H-G, Knecht S (2009a) Synergetic effects of granulocyte-colony stimulating factor and cognitive training on spatial learning and survival of newborn hippocampal neurons. PLoS One 4:e5303.

Diederich K, Sevimli S, Dörr H, Kösters E, Hoppen M, Lewejohann L, Klocke R, Minnerup J, Knecht S, Nikol S, Sachser N, Schneider A, Gorji A, Sommer C, Schäbitz WR (2009b) The role of granulocyte-colony stimulating factor (G-CSF) in the healthy brain: a characterization of G-CSFdeficient mice. J Neurosci 29:11572-11581.

Dong Y, Taylor JR, Wolf ME, Shaham Y (2017) Circuit and synaptic plasticity mechanisms of drug relapse. J Neurosci 37:10867-10876.

Dörrbaum AR, Kochen L, Langer JD, Schuman EM (2018) Local and global influences on protein turnover in neurons and glia. Elife 7:e34202.

Farokhnia M, Berger AL, Karoly HC, Hwa LS, Varodayan FP (2020) The promise of neuroimmune targets for treating drug addiction and other psychiatric disorders: granulocyte-colony stimulating factor exemplification. Front Psychiatry 11:220.

Farrell MR, Schoch H, Mahler SV (2018) Modeling cocaine relapse in rodents: behavioral considerations and circuit mechanisms. Prog Neuropsychopharmacol Biol Psychiatry 87:33-47.

Ghazalpour A, Bennett B, Petyuk VA, Orozco L, Hagopian R, Mungrue IN, Farber CR, Sinsheimer J, Kang HM, Furlotte N, Park CC, Wen PZ, Brewer H, Weitz K, Camp DG, Pan C, Yordanova R, Neuhaus I, Tilford C, Siemers N, et al. (2011) Comparative analysis of proteome and transcriptome variation in mouse. PLoS Genet 7:e1001393.

Grimm JW, Hope BT, Wise RA, Shaham Y (2001) Neuroadaptation. Incubation of cocaine craving after withdrawal. Nature 412:141-142.

Hamilton DA, Brigman JL (2015) Behavioral flexibility in rats and mice: contributions of distinct frontocortical regions. Genes Brain Behav 14:4-21.

Han J, Kollmar R, Tobyas B, Schwab S (2008) Inhibited glutamate release by granulocyte-colony stimulating factor after experimental stroke. Neurosci Lett 432:167-169.

Hodes GE, Kana V, Menard C, Merad M, Russo SJ (2015) Neuroimmune mechanisms of depression. Nat Neurosci 18:1386-1393.

Hofford RS, Russo SJ, Kiraly DD (2019) Neuroimmune mechanisms of psychostimulant and opioid use disorders. Eur J Neurosci 50:2562-2573.

Hoggatt J, Pelus LM (2014) New G-CSF agonists for neutropenia therapy. Expert Opin Investig Drugs 23:21-35.

Hu A, Noble WS, Wolf-Yadlin A (2016) Technical advances in proteomics: new developments in data-independent acquisition. F1000Res 5:419.

Huang CC, Lin HJ, Hsu KS (2007) Repeated cocaine administration promotes long-term potentiation induction in rat medial prefrontal cortex. Cereb Cortex 17:1877-1888. 
Hyman SE, Malenka RC, Nestler EJ (2006) Neural mechanisms of addiction: the role of reward-related learning and memory. Annu Rev Neurosci 29:565-598.

Kalivas PW, McFarland K (2003) Brain circuitry and the reinstatement of cocaine-seeking behavior. Psychopharmacology (Berl) 168:44-56.

Kalivas PW, Volkow N, Seamans J (2005) Unmanageable motivation in addiction: a pathology in prefrontal-accumbens glutamate transmission. Neuron 45:647-650.

Koya E, Uejima JL, Wihbey KA, Bossert JM, Hope BT, Shaham Y (2009) Role of ventral medial prefrontal cortex in incubation of cocaine craving. Neuropharmacology 56 [Suppl 1]:177-185.

Kumar D, Bansal G, Narang A, Basak T, Abbas T, Dash D (2016) Integrating transcriptome and proteome profiling: strategies and applications. Proteomics 16:2533-2544.

Kutlu MG, Brady LJ, Peck EG, Hofford RS, Yorgason JT, Siciliano CA, Kiraly DD, Calipari ES (2018) Granulocyte colony stimulating factor enhances reward learning through potentiation of mesolimbic dopamine system function. J Neurosci 38:8845-8859.

Lacagnina MJ, Rivera PD, Bilbo SD (2017) Glial and neuroimmune mechanisms as critical modulators of drug use and abuse. Neuropsychopharmacology 42:156-177.

Mammele S, Frauenknecht K, Sevimli S, Diederich K, Bauer H, Grimm C, Minnerup J, Schäbitz WR, Sommer C1 (2016) Prevention of an increase in cortical ligand binding to AMPA receptors may represent a novel mechanism of endogenous brain protection by G-CSF after ischemic stroke. Restor Neurol Neurosci 34:665-675.

Mervosh NL, Wilson R, Rauniyar N, Hofford RS, Kutlu MG, Calipari ES, Lam TT, Kiraly DD (2018) Granulocyte-colony-stimulating factor alters the proteomic landscape of the ventral tegmental area. Proteomes 6:35.

Meuer K, Pitzer C, Teismann P, Krüger C, Göricke B, Laage R, Lingor P, Peters K, Schlachetzki JCM, Kobayashi K, Dietz GPH, Weber D, Ferger B, Schäbitz WR, Bach A, Schulz JB, Bähr M, Schneider A, Weishaupt JH (2006) Granulocyte-colony stimulating factor is neuroprotective in a model of Parkinson's disease. J Neurochem 97:675-686.

Miller BJ, Goldsmith DR (2017) Towards an immunophenotype of schizophrenia: progress, potential mechanisms, and future directions. Neuropsychopharmacology 42:299-317.

Parvaz MA, Moeller SJ, Goldstein RZ (2016) Incubation of cue-induced craving in adults addicted to cocaine measured by electroencephalography. JAMA Psychiatry 73:1127-1134.

Payne SH (2015) The utility of protein and mRNA correlation. Trends Biochem Sci 40:1-3.

Penberthy JK, Ait-Daoud N, Vaughan M, Fanning T (2010) Review of treatment for cocaine dependence. Curr Drug Abuse Rev 3:49-62.

Perez-Riverol Y, Csordas A, Bai J, Bernal-Llinares M, Hewapathirana S, Kundu DJ, Inuganti A, Griss J, Mayer G, Eisenacher M, Pérez E, Uszkoreit J, Pfeuffer J, Sachsenberg T, Yilmaz S, Tiwary S, Cox J, Audain E, Walzer M, Jarnuczak AF, et al. (2019) The PRIDE database and related tools and resources in 2019: improving support for quantification data. Nucleic Acids Res 47:D442-D450.
Peters J, Kalivas PW, Quirk GJ (2009) Extinction circuits for fear and addiction overlap in prefrontal cortex. Learn Mem 16:279-288.

Raudvere U, Kolberg L, Kuzmin I, Arak T, Adler P, Peterson H, Vilo J (2019) g: profiler: a web server for functional enrichment analysis and conversions of gene lists (2019 update). Nucleic Acids Res 47:W191-W198.

Ridwan S, Bauer H, Frauenknecht K, Hefti K, von Pein H, Sommer CJ (2014) Distribution of the hematopoietic growth factor G-CSF and its receptor in the adult human brain with specific reference to Alzheimer's disease. J Anat 224:377-391.

Schäbitz WR, Kollmar R, Schwaninger M, Juettler E, Bardutzky J, Schölzke MN, Sommer C, Schwab S (2003) Neuroprotective effect of granulocyte colony-stimulating factor after focal cerebral ischemia. Stroke 34:745751.

Schwanhäusser B, Busse D, Li N, Dittmar G, Schuchhardt J, Wolf J, Chen W, Selbach M (2011) Global quantification of mammalian gene expression control. Nature 473:337-342.

Searle BC, Pino LK, Egertson JD, Ting YS, Lawrence RT, Villen J, MacCoss MJ (2018) Comprehensive peptide quantification for data independent acquisition mass spectrometry using chromatogram libraries. bioRxiv. doi: $10.1101 / 277822$.

Shin CB, Serchia MM, Shahin JR, Ruppert-Majer MA, Kippin TE, Szumlinski KK (2016) Incubation of cocaine-craving relates to glutamate over-flow within ventromedial prefrontal cortex. Neuropharmacology 102:103-110.

Shin CB, Templeton TJ, Chiu AS, Kim J, Gable ES, Vieira PA, Kippin TE, Szumlinski KK (2018) Endogenous glutamate within the prelimbic and infralimbic cortices regulates the incubation of cocaine-seeking in rats. Neuropharmacology 128:293-300.

Sinha R (2011) New findings on biological factors predicting addiction relapse vulnerability. Curr Psychiatry Rep 13:398-405.

Stefanik MT, Moussawi K, Kupchik YM, Smith KC, Miller RL, Huff ML, Deisseroth K, Kalivas PW, LaLumiere RT (2013) Optogenetic inhibition of cocaine seeking in rats. Addict Biol 18:50-53.

Supek F, Bošnjak M, Škunca N, Šmuc T (2011) REVIGO summarizes and visualizes long lists of gene ontology terms. PLoS One 6:e21800.

Szklarczyk D, Gable AL, Lyon D, Junge A, Wyder S, Huerta-Cepas J, Simonovic M, Doncheva NT, Morris JH, Bork P, Jensen LJ, Mering C. v (2019) STRING v11: protein-protein association networks with increased coverage, supporting functional discovery in genome-wide experimental datasets. Nucleic Acids Res 47:D607-D613.

Szumlinski KK, Wroten MG, Miller BW, Sacramento AD, Cohen M, BenShahar O, Kippin TE (2016) Cocaine self-administration elevates GluN2B within dmPFC mediating heightened cue-elicited operant responding. J Drug Abus 2:22.

Wilson RS, Rauniyar N, Sakaue F, Lam TT, Williams KR, Nairn AC (2019) Development of targeted mass spectrometry-based approaches for quantitation of proteins enriched in the postsynaptic density (PSD). Proteomes 7:12. 